\title{
Yellow fever cases in French Guiana, evidence of an active circulation in the Guiana Shield, 2017 and 2018
}

Alice Sanna ${ }^{1}$, Audrey Andrieu², Luisiane Carvalho², Claire Mayence ${ }^{3}$, Philippe Tabard ${ }^{1}$, Marina Hachouf ${ }^{4}$, Claire-Marie Cazaux Antoine Enfissi ${ }^{5}$, Dominique Rousset ${ }^{5}$, Hatem Kallel ${ }^{3}$

1. Public health direction, Regional Health Agency (Agence régionale de santé Guyane), Cayenne, French Guiana

2. Regional Unit of Santé publique France (France's national public health agency), Cayenne, French Guiana

3. Intensive Care Unit, Cayenne Hospital, French Guiana

4. APHP-HUPNVS, Department of Anesthesiology and Critical Care, Beaujon Hospital, Clichy, France

5. National Reference Laboratory for Arboviruses, Institut Pasteur de la Guyane, Cayenne, French Guiana

Correspondence: Alice Sanna (a.sanna33@gmail.com)

Sanna Alice, Andrieu Audrey, Carvalho Luisiane, Mayence Claire, Tabard Philippe, Hachouf Marina, Cazaux Claire-Marie, Enfissi Antoine, Rousset Dominique, Kallel Hatem. Yellow fever cases in French Guiana, evidence of an active circulation in the Guiana Shield, 2017 and 2018. Euro Surveill. 2018;23(36):pii=1800471. https:// doi.org/10.2807/1560-7917.ES.2018.23.36.1800471

French Guiana (FG) is a French overseas region bordering Brazil and Suriname that is considered endemic for yellow fever (YF); vaccination is compulsory for residents and travellers. In August 2017 and 2018, two sporadic YF cases were notified 1 year apart, confirming that sylvatic YF virus circulation is active in the region. YF vaccination coverage should be closely monitored and improved in FG and neighbouring territories and clinicians should be aware of the risk.

In August 2017 and 2018 respectively, sporadic yellow fever (YF) cases were reported in French Guiana (FG). Previously, the last autochthonous case was notified in 1998 , in the south-east of FG [1]. Here we describe the clinical and epidemiological features of the two recent YF cases, as well as public health measures implemented.

\section{Case 1: Enigmatic case from a clandestine} gold-mining site, August 2017

The case was a Brazilian woman in her mid-40s who lived and worked in a clandestine, small-scale, gold prospecting site (garimpo) in the forested area of the dam lake Petit Saut. In July 2017, she spent ca 1 month in the Amapá state in Brazil, before crossing the border at Oiapoque about 15 days before admission to hospital. She returned to Kourou by sea, continued to travel by land and reached the garimpo about 12 days before her admission to Kourou hospital on 7 August 2017 (Figure). She was reported by close contacts at the mining site as initially being either healthy or mildly ill (divergent statements were given). Approximately 5 days before hospitalisation, she reported fever, lumbar and abdominal pain, vomiting and a profound asthenia; relatives witnessed haemorrhagic symptoms (macroscopic haematuria and haematemesis).
The case was admitted at the emergency ward of the Kourou hospital on 7 August, and on 8 August she was transferred to the intensive care unit (ICU) of the hospital in the capital Cayenne due to fulminant hepatitis associated with multi-organ failure. She did not respond to intense supportive therapy and passed away on 9 August. We found no evidence of a former YF vaccination.

A real-time PCR [2] performed on 21 August on a blood sample collected on 8 August allowed confirmation of YF by the arboviruses national reference laboratory (CNR) of the FG Pasteur Institute (IPG) (Table).

Due to the language barrier and mistrust, likely associated with the clandestine gold-prospecting operation, the epidemiological investigation with the patient's contacts was complex. Given the uncertainty of the results, in particular travel itinerary and onset of symptoms, and considering different scenarios for the incubation time and sickness duration [3,4], we speculated that the infection might have occurred either in the Amapá state in Brazil or in FG (Petit Saut dam lake area).

\section{Epidemiological investigation}

Passive epidemiological surveillance was strengthened in order to identify possible secondary cases. Moreover, among the locations frequented by the patient while viraemic, only one residential area, in the vicinity of Kourou's Hospital (range 100 m), was identified where it was possible to perform active case finding. One restaurant and 23 households were identified, of which 15 could be investigated. All of the 41 traced persons were vaccinated against YF, with the exception of two newborns who were asymptomatic. 
Map with sites of onset of symptoms for notified yellow fever cases and the approximate travel route of the 2017 yellow fever case, French Guiana, 1998-2018 (n=3 cases)

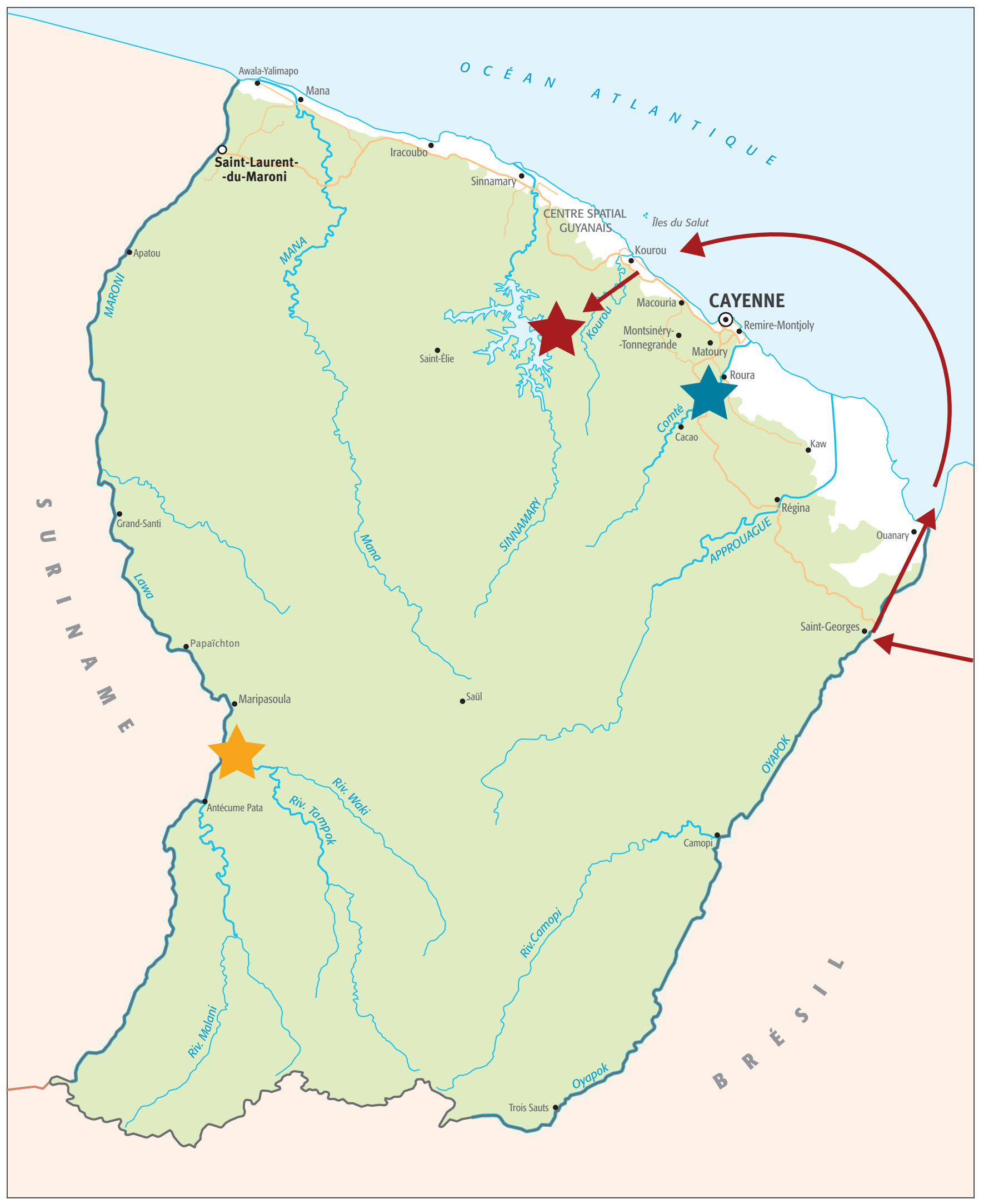

Yellow star: 1998 yellow fever case; red star: 2017 yellow fever case; blue star: 2018 yellow fever case.

Modified from IGN 2012 map - Licence ouverte. 
Laboratory results for infectious aetiologies for yellow fever cases, French Guiana, 2017 and $2018(\mathrm{n}=2)$

\begin{tabular}{|c|c|c|}
\hline Infectious aetiologies & Case 1 & Case 2 \\
\hline Yellow fever virus & PCR (blood) pos, IgG neg, IgM pos & PCR (blood) pos, IgG neg, IgM pos \\
\hline Zika virus & PCR neg, IgG neg, IgM neg & IgG neg, IgM neg \\
\hline Chikungunya virus & PCR neg, IgG neg, IgM neg & IgG neg, IgM neg \\
\hline Dengue virus & Antigen NS1 neg, IgG neg, IgM neg & IgG neg, IgM neg \\
\hline Blood cultures for bacteria & Neg & Neg \\
\hline Blood cultures for fungi & $\mathrm{Neg}$ & NA \\
\hline Leptospirosis & PCR (urine and blood) neg & PCR (blood) neg \\
\hline Plasmodium spp. & Microscopy neg & Microscopy neg \\
\hline Toxoplasma gondii & $\lg G$ pos, IgM neg & NA \\
\hline Trypanosoma cruzi & IgG neg & NA \\
\hline Herpes simplex virus $1 / 2$ & $\lg G$ pos, IgM neg & NA \\
\hline Varicella zoster virus & NA & IgG pos, IgM neg \\
\hline Cytomegalovirus & IgG pos, IgM neg & IgG pos/neg, IgM neg \\
\hline Epstein-Barr virus & NA & $\begin{array}{l}\text { IgG anti-EBNA pos, IgG anti-VCA pos, IgM anti- } \\
\text { VCA neg }\end{array}$ \\
\hline Hepatitis A virus & Total Ig pos, IgM neg & Total Ig neg, IgM neg \\
\hline Hepatitis $B$ virus & $\begin{array}{c}\text { HBsAg neg, anti-HBs neg, anti-HBC } \\
\text { neg }\end{array}$ & HBsAg neg, anti-HBs neg, anti-HBc neg \\
\hline Hepatitis C virus & Total Ig neg & Total Ig neg \\
\hline Human immunodeficiency virus & Ag P24 neg, serology neg & PCR neg \\
\hline Human T-lymphotropic virus & Ig neg & NA \\
\hline
\end{tabular}

EBNA: anti-EBV nuclear antigen-1; Ig: Immuno-globulins; NA: Not available; PCR: polymerase chain reaction; VCA: Viral Capsid Antigen Antibody.

\section{Case 2: European traveller in the Amazonian forest, August 2018}

The case was a Swiss man, in his late 40s, who supposedly reached FG by land in April 2018 after a long trip in South America. For several weeks he lived in a forest dwelling near the river Comté (Roura municipality). He was reported to have worked on a trail development in the same area the week preceding symptom onset. He reportedly developed mild symptoms (fever, body aches and myalgia) on 4 August. He first sought medical help the following day and was discharged with the diagnosis of acute dengue-like viral infection. He subsequently developed vomiting and deep prostration, associated with persisting high fever and visited the emergency room of the Cayenne hospital on 7 August. He was admitted to the ICU on 8 August due to renal and hepatic failure. On 9 August, he was transferred to a specialised transplant centre close by Paris in mainland France, to receive a hepatic transplant. Despite this he unfortunately died on 30 August. The patient was not vaccinated against YF.

On 10 August, both RT-PCR and serological tests were performed on a blood sample collected on 8 August by the arboviruses CNR of the IPG [2] confirming the diagnosis YF (Table).
In this case, the transmission was clearly autochthonous and sylvatic, occurring in the north of FG, ca $40 \mathrm{~km}$ from Cayenne.

\section{Epidemiological investigation}

Active case finding was carried out in the neighbourhood where the case lived. The area is sparsely populated, and only six potentially co-exposed persons were identified, all of them were vaccinated against YF.

In the area there are, however, several touristic structures, and tourists or other people potentially coexposed e.g. while participating in outdoor sports in the area will be targeted for passive epidemiological surveillance supported by a reporting device.

\section{Public health measures}

For both cases, soon after YF confirmation, vector control measures were strengthened in the locations where the patients transited while viraemic. Information campaigns encouraging vaccination have been carried out in FG, aimed at the general population and clinicians; this communication has been strengthened towards people living and working in areas attended by the cases.

Already since March 2017, we have solicited inhabitants and partner institutions that regularly work in the Amazonian forest (i.e. Amazonian park, French army 
or organisations dedicated to the preservation of the environment), and they have not reported any evidence of unusual mortality in the non-human primates (NHP) population; nevertheless, in FG, no structured surveillance system of sylvatic epizootics exists.

Illegal gold prospectors were an at-risk, potentially unvaccinated and hard-to-reach population. They live deep in the forest and are potentially co-exposed to the YF virus. Moreover, working in illegal sites and often targeted by police operations they are difficult to reach by health professionals. When the first case occurred, we collaborated with local health and social mediators to invite members of this community who were active near Petit Saut dam lake, to receive vaccination against YF free of charge in nearby health centres. The Kourou health centre of the French Red Cross reportedly received several garimpeiros seeking vaccination in the following weeks (exact figures not available). Garimpeiros were advised to seek medical care immediately if they developed consistent symptoms: four consulted for fever with an unknown vaccination status, and tested negative for YF PCR.

\section{Discussion}

French Guiana is a French overseas region bordering Brazil and Suriname. It is the only European territory geographically located in the Amazonian region, and considered endemic for yellow fever (YF) [5]. The confirmation of two human YF cases unusually close in time confirms that sylvatic YF circulation is currently occurring in this region.

In 2017, epizootics and sporadic human cases were observed in the northern part of the nearby state of Pará, Brazil [6]; a recent case in neighbouring Suriname was identified in the Brokopondo lake area [7], less than $100 \mathrm{~km}$ away from its border with FG. These data suggest ongoing viral circulation in the wider Guiana Shield region. It is not clear, however, whether this is linked with the major epidemics recently observed in the south-eastern region of Brazil $[6,8,9]$.

As the surrounding territories in the Amazonian region, FG is exposed to the risk of both sylvatic (observed) and urban (potential) YF [10]. A sylvatic circulation of YF virus in FG was documented in 1994-95, in a study showing a seroprevalence of $26-35 \%$ among NHP in the Petit Saut lake dam forest [11], and was in favour of cyclic and recurrent epizootics [12]. Aedes aegypti, an urban vector for YF virus, is largely present in FG [10]. The last documented evidence of human epidemic transmission in an urban context in FG dates back to $1902[1,13]$.

Since 1967, YF vaccination has been compulsory for everyone above 1 year of age living in or travelling to FG (airport vaccination status controls are in place) [14]. The latest regional vaccination coverage estimates available for $\mathrm{FG}$ range from $80-90 \%$ to more than $95 \%$ [15]. These figures are in line with the World Health
Organization targets of a $60-80 \%$ immunisation coverage to avoid major YF epidemics [16], but are not fully satisfactory considering the regional $95 \%$ coverage target.

Vaccination coverage should be improved particularly in persons living and working in the forest, who are exposed during the day to sylvatic vectors [17]. It should also be improved in migrants and other vulnerable populations who are more susceptible to being unvaccinated and live in densely populated urban areas (with a risk of urban local transmission), or participate to illegal activities in the forest (with a risk of sporadic cases or clusters in a sylvatic context). A recent random-sampling, whole-population survey will produce vaccination coverage estimates to assist health authorities in targeting at-risk populations.

Despite the relative rarity of the disease, and the complex tropical epidemiological context, clinicians should take YF into account as differential diagnosis when encountering non-vaccinated patients with fever and symptoms compatible with YF, living in or returning from FG. Additional strengthening of laboratory and clinical vigilance in FG may also allow for the detection of sporadic (and even non-severe) cases, which might otherwise remain undiagnosed: severe (ca 12\% of YF virus infections) and deadly cases are likely only the tip of the iceberg [18]. Adherence to timely mandatory reporting will enable public health authorities to implement early control measures, and prevent further spread of the disease.

\section{Acknowledgements \\ We would like to thanks Domacia Silva, Cecilia Dos Santos and José 'Dédé' Gomes for their precious help in mediation and translation; Priscila, for her courage; Denise Antona and Fabrice Quet for their advice and proofreading; all the health professionals of the Cayenne and Kourou hospitals who con- tributed to the medical care of these patients; and the teams of the ARS, SpFrance, CTG and CRF for their participation to field investigations and control measures.}

\section{Conflict of interest}

None declared.

\section{Authors' contributions}

$A S, A A, L C$ and $C M C$ were involved in epidemiological investigations. $A E$ and $D R$ were involved in laboratory investigations. $\mathrm{CM}, \mathrm{MH}$ and $\mathrm{HK}$ were involved in clinical management of patients. AS, PT and CMC were involved in control measures. AS, AA, LC, AE, DR and HK contributed to the conception of the manuscript, drafted by AS. All authors read, revised and approved the final manuscript.

\section{References}

1. Heraud JM, Hommel D, Hulin A, Deubel V, Poveda JD, Sarthou JL, et al. First case of yellow fever in French Guiana since 1902. 
Emerg Infect Dis. 1999;5(3):429-32. https://doi.org/10.3201/ eido503.990314 PMID: 10341180

2. Weidmann M, Faye O, Faye O, Kranaster R, Marx A, Nunes MRT, et al. Improved LNA probe-based assay for the detection of African and South American yellow fever virus strains. J Clin Virol. 2010;48(3):187-92. https://doi.org/10.1016/j. jCv.2010.04.013 PMID: 20556888

3. Monath TP, Vasconcelos PFC. Yellow fever. J Clin Virol. 2015;64:160-73. https://doi.org/10.1016/j.jcv.2014.08.030 PMID: 25453327

4. Johansson MA, Arana-Vizcarrondo N, Biggerstaff BJ, Staples JE. Incubation periods of Yellow fever virus. Am Trop Med Hyg. 2010;83(1):183-8. https://doi.org/10.4269/ ajtmh.2010.09-0782 PMID: 20595499

5. Jentes ES, Poumerol G, Gershman MD, Hill DR, Lemarchand J, Lewis RF, et al. Informal WHO Working Group on Geographic Risk for Yellow Fever. The revised global yellow fever risk map and recommendations for vaccination, 2010: consensus of the Informal WHO Working Group on Geographic Risk for Yellow Fever. Lancet Infect Dis. 2011;11(8):622-32. https://doi. org/10.1016/S1473-3099(11)70147-5 PMID: 21798462

6. Ministério da Saúde - Secretaria de Vigilância em Saúde. Monitoramento do Período Sazonal da Febre Amarela Brasil 2017/2018. Informe 26. [Monitoring of the seasonal period of yellow fever in Brazil - 2017-2018. Report 26]. [Accessed: 15 Aug 2018]. Portuguese. Available from: http://portalarquivos2. saude.gov.br/images/pdf/2018/maio/18/Informe-FA-26.pdf

7. Wouthuyzen-Bakker M, Knoester M, van den Berg AP, GeurtsvanKessel CH, Koopmans MP, Van Leer-Buter C, et al. Yellow fever in a traveller returning from Suriname to the Netherlands, March 2017. Euro Surveill. 2017;22(11):30488. https://doi.org/10.2807/1560-7917.ES.2017.22.11.30488 PMID: 28333617

8. Rezende IM, Sacchetto L, Munhoz de Mello É, Alves PA, Iani FCM, Adelino TÉR, et al. Persistence of Yellow fever virus outside the Amazon Basin, causing epidemics in Southeast Brazil, from 2016 to 2018. PLoS Negl Trop Dis 2018;12(6):e0006538. https://doi.org/10.1371/journal. pntd.0006538 PMID: 29864115

9. Mir D, Delatorre E, Bonaldo M, Lourenço-de-Oliveira R, Vicente AC, Bello G. Phylodynamics of Yellow Fever Virus in the Americas: new insights into the origin of the 2017 Brazilian outbreak. Sci Rep. 2017;7(1):7385. https://doi.org/10.1038/ s41598-017-07873-7 PMID: 28785067

10. Epelboin Y, Chaney SC, Guidez A, Habchi-Hanriot N, Talaga $\mathrm{S}$, Wang $\mathrm{L}$, et al. Successes and failures of sixty years of vector control in French Guiana: what is the next step? Mem Inst Oswaldo Cruz. 2018;113(5):e170398. https://doi. org/10.1590/0074-02760170398 PMID: 29538490

11. de Thoisy B, Vogel I, Reynes JM, Pouliquen JF, Carme B, Kazanji $M$, et al. Health evaluation of translocated free-ranging primates in French Guiana. Am J Primatol. 2001;54(1):1-16. https://doi.org/10.1002/ajp.1008 PMID: 11329164

12. Kean S. On the trail of yellow fever. Science. 2017;357(6352):637-41. https://doi.org/10.1126/ science.357.6352.637 PMID: 28818926

13. Garnier A. La fièvre jaune à la Guyane avant 1902 et l'épidémie de 1902. [Yellow fever in French Guiana before 1902 and the 1902 outbreak]. Paris: Imprimerie nationale; 1903. French.

14. World Health Organization (WHO). RESOLUTION WHA67.13 Implementation of the International Health Regulations (2005). Geneva: WHO; 2014. Available from: http://www.who.int/ith/ A67_2014_Annex-7-en.pdf?ua=1

15. Vallet B, Antona D, Quet F, Herida M, Comolet T. Yellow fever vaccination coverage in French Guiana. Lancet Infect Dis. 2018;18(1):28. https://doi.org/10.1016/S1473-3099(17)30701-6 PMID: 29303736

16. World health Organisation (WHO). Eliminate Yellow fever Epidemics (EYE): a global strategy, 2017-2026. Geneva: WHO; 2018. Available from: http://apps.who.int/iris/bitstream/hand le/10665/272408/9789241513661-eng.pdf?ua=1

17. Pinto CS, Confalonieri UEC, Mascarenhas BM. Ecology of Haemagogus sp. and Sabethes sp. (Diptera: Culicidae) in relation to the microclimates of the Caxiuanã National Forest, Pará, Brazil. Mem Inst Oswaldo Cruz. 2009;104(4):592-8. https://doi.org/10.1590/So074-02762009000400010 PMID: 19722082

18. Johansson MA, Vasconcelos PFC, Staples JE. The whole iceberg: estimating the incidence of yellow fever virus infection from the number of severe cases. Trans R Soc Trop Med Hyg. 2014;108(8):482-7. https://doi.org/10.1093/trstmh/truo92 PMID: 24980556

\section{License and copyright}

This is an open-access article distributed under the terms of the Creative Commons Attribution (CC BY 4.0) Licence. You may share and adapt the material, but must give appropriate credit to the source, provide a link to the licence, and indicate if changes were made.

This article is copyright of the authors or their affiliated institutions, 2018. 